\title{
Spatial distribution of net surface mass balance on Greenland
}

\author{
H.J. Zwally, ${ }^{1}$ M. B. Giovinetto ${ }^{2}$ \\ ${ }^{1}$ NASA Goddard Space Flight Center, Code 971, Greenbelt, MD 20771, U.S.A. \\ ${ }^{2}$ Raytheon ITSS, NASA Goddard Space Flight Center, Code 971, Greenbelt, MD 20771, U.S.A.
}

\begin{abstract}
The spatial distribution of surface mass balance on the Greenland ice sheet is mapped on a $50 \mathrm{~km}$ grid using a combination of methods depending on a zonal characterization of the diagenetic snow facies. In the zones of dry snow and upper percolation facies, the accumulation rate is calculated from microwave emissivities derived from satellite measurements using a model that is calibrated with field accumulation data. In the lower percolation zone, accumulation rates are obtained from visual interpolation of previously compiled field data, with some modification so the balance is zero at the equilibrium line. In the ablation zone, ablation rates are calculated as a function of ice-surface elevation and latitude. Average values of the surface balance are $263 \mathrm{~kg} \mathrm{~m}^{-2} \mathrm{a}^{-1}$ in the accumulation zone, $(-) 1259 \mathrm{~kg} \mathrm{~m}^{-2} \mathrm{a}^{-1}$ in the ablation zone and $128 \mathrm{~kg} \mathrm{~m}^{-2} \mathrm{a}^{-1}$ overall. Compared to the findings of a previous study using practically the same approach but different models, our bulk estimate of balance $\left(216 \mathrm{Gt} \mathrm{a}^{-1}\right)$ is $57 \%$ smaller, but the differences in the estimates of net accumulation and net ablation are, respectively, $30 \%$ and $172 \%$ larger. In this and other comparisons, there is evidence that the differences in estimates are primarily due to differences in the delineation of the equilibrium line and the estimate of ablation, and secondarily to the estimate of accumulation and interpolation of field data. The differences noted with six other estimates reported in the last two decades are all of a size close to the composite variation of the difference $\left( \pm 50 \mathrm{Gt} \mathrm{a}^{-1}\right)$. Our surface balance is smaller than three estimates, larger than one and in agreement with two. If substituted in the latest mass-budget estimate that indicates equilibrium, our surface balance estimate would suggest a negative budget of $55 \mathrm{Gt} \mathrm{a}^{-1}$ and thus a positive contribution to sea-level change of $0.15 \mathrm{~mm} \mathrm{a}^{-1}$.
\end{abstract}

\section{INTRODUCTION}

Glaciological and climatological studies of the Greenland ice sheet are an important part of the research on the role of the cryosphere in global change (e.g. Oeschger and Langway, 1989; Ohmura and others, 1996). Modeling is one of the principal contributions to these studies, and the usefulness of the findings is dependent on the reliability of the datasets used for particular variables. In this study, we present the spatial distribution of the mean annual surface mass balance. Surface mass balance is defined as the difference between the sum of the mass-gain processes, including precipitation, condensation, vapor-to-solid sublimation, deposition of blowing snow, and freezing of rain or surface runoff as superimposed ice, and the sum of the mass-loss processes, including evaporation, sublimation, surface-melt runoff and snow deflation (removal by wind). In the accumulation zone where the surface mass balance is positive, the surface balance is usually called the net accumulation rate. In the ablation zone where the surface mass balance is negative, the surface balance is usually called the net ablation rate.

The surface mass balance is determined for gridpoint locations with $50 \mathrm{~km}$ spacing (Fig. $1 ; N=682$, where $N$ is the number of gridpoints in a dataset). The gridpoint locations correspond to the intersection of gridlines and gridcolumns that are, respectively, normal and parallel to the $45^{\circ} \mathrm{W}$ meridian. The point of origin for line spacing is the
North Pole. Latitude and longitude for each gridpoint are determined for a polar stereographic projection with standard line at $71^{\circ} \mathrm{N}$. Each location is centered on a $50 \mathrm{~km} \times 50 \mathrm{~km}$ grid square with a nominal area of $2500 \mathrm{~km}^{2}$, and true grid areas are calculated with a latitude-dependent scale factor derived for the projection (Pinther, 1975).

The conterminous area of Greenland, excluding islands not attached by ice to the mainland, is fully sampled by 849 gridpoints. Of these, 682 points are on the conterminous ice sheet. The other 167 points are on exposed rock and ice caps not attached to the ice sheet and also excluded from the icesheet analysis (Fig. 2). The locations are categorized from plots of the peripheral gridpoints on the latest coastline and ice-termini map (Weidick, 1995; 1:2.5 × 106 ; Universal Transverse Mercator projection zone 24; central meridian $39^{\circ} \mathrm{W}$ ).

The ice-sheet dataset is delineated on the basis of zonation of diagenetic snow facies (e.g. Benson, 1962) (Fig. 1). The three principal indicators for the zone delineation are combinations of at least two of the following: surface elevation, mean annual surface temperature and latitude. The surface elevation for each gridpoint is obtained by bilinear interpolation from the European remote-sensing satellite (ERS-1) radar altimeter elevation maps (Zwally and Brenner, 1999). The mean annual surface temperature for each gridpoint is obtained by bilinear interpolation from the Nimbus 7 temperature humidity infrared radiometer (THIR) database for 1979 (Comiso, 1994). Since 1979 is the only full year 


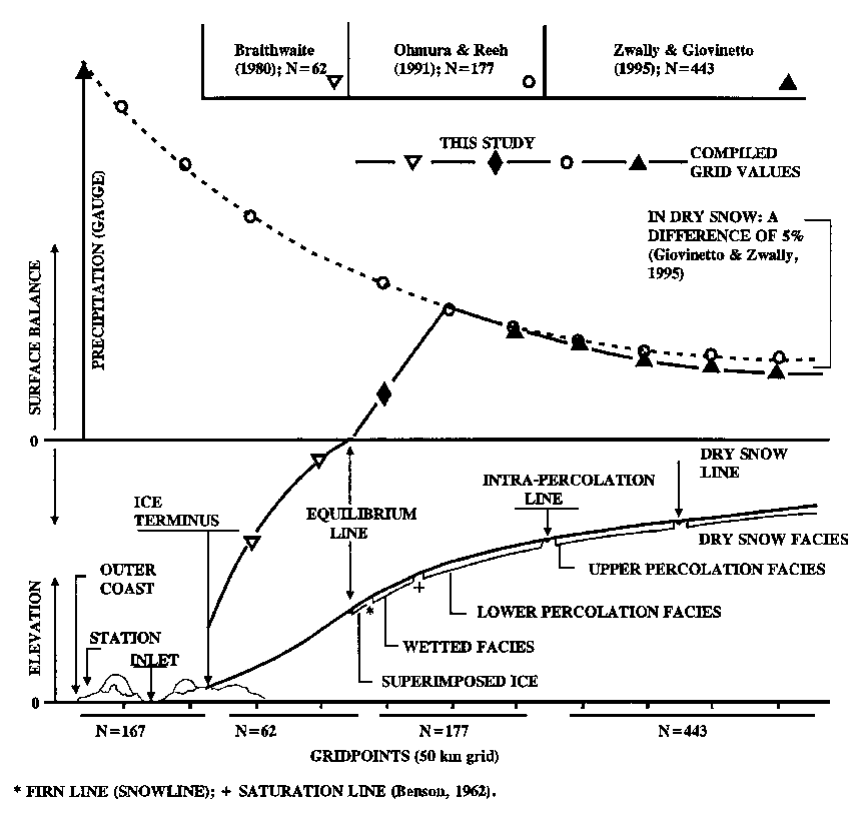

Fig. 1. Schematic distribution of ice-sheet zones of diagenetic snow facies and the surface balance. In the dry-snow and upper percolation zones for $N=443$ points, the balance is determined with a microwave-emissivity accumulation model and satellite measurements of emissivity (Zwally and Giovinetto, 1995). For $N=62$ gridpoints in the ablation zone (seaward of the equilibrium line), the balance is calculated as function of elevation and latitude (Braithwaite, 1980). The balance for $N=$ 177 points in between these areas is obtained from a compilation of field data (Ohmura and Reeh, 1991), modified by simple linear interpolation to have values of zero at the equilibrium line.

of THIR data analyzed, its variability relative to other years is not known. However, in another analysis using a $100 \mathrm{~km}$ grid database for the conterminous ice sheet $(N=187)$, we found that the THIR temperatures (Ta'79, in K) strongly correlated with the mean annual surface temperature (Taf, in $\mathrm{K}$ ) that was visually interpolated to gridpoints from an isotherm map drawn by Ohmura (1987). The isotherms were drawn on the basis of data for 27 coastal and 20 interior stations, standardized for the period 1951-60 and interpolated on the basis of latitude and elevation using three lapse-rate determinations for latitudes of $65^{\circ}, 70^{\circ}$ and $75^{\circ} \mathrm{N}$. The data for two stations on the ice sheet, as well as firn-temperature measurements at $10 \mathrm{~m}$ depth, were used for evaluation of the isotherms, but not in the production of the isotherm maps. It should be noted that the use of firn temperatures to draw annual isotherms is limited to the areas of dry snow and upper percolation facies, or approximately one-half the area of the ice sheet $(N=98$ in the $100 \mathrm{~km}$ grid). Our correlation between Ta'79 and Taf was: correlation coefficient, $R=0.949$; root-mean-square residual, $\mathrm{rms}=1.8 \mathrm{~K}$; mean of temperature residual (Taf - Ta' 79) $=1.0 \mathrm{~K}$; standard deviation, $\mathrm{SD}=2.7 \mathrm{~K}$ ).

\section{SURFAGE MASS-BALANGE DISTRIBUTION}

Our new surface balance dataset for the $50 \mathrm{~km}$ grid $(N=682)$ is first compiled in digitized format (Fig. 2) and then contoured (Fig. 3). In the dry-snow zone and the area of upper percolation facies $(N=443$ total), the balance rate is calculated as a function of firn emissivity (Zwally, 1977) using a model developed for Greenland (Zwally and Giovinetto, 1995). The coefficients in the model were determined using field data for 89 sites in the areas of dry snow, in effect calibrating the model to the field data. The firn emissivities are calculated from the mean annual surface temperature and brightness temperatures obtained, respectively, from the Nimbus 7 THIR database for 1979 (Comiso, 1994) already mentioned and by bilinear interpolation from the Nimbus 5 electrically scanning microwave radiometer (ESMR) database for 1973-76 (Parkinson and others, 1987). A robust correlation between the balance values derived from the emissivity model and the field data in the area of dry snow $\left(R=0.891 ; \mathrm{rms}=36 \mathrm{~kg} \mathrm{~m}^{-2} \mathrm{a}^{-1}\right.$; Zwally and Giovinetto, 1995) is also reliable in large parts of the area of upper percolation. The location of the dry-snow line and of the intra-percolation line are inferred, with minor modifications, from the facies zonation described by Benson (1962) as function of elevation and latitude.

Ablation is calculated as a function of elevation and latitude with a model that was developed on the basis of data from West Greenland (Braithwaite, 1980; also shown in Weidick, 1995), giving minimum rates of net ablation for points $(N=62)$ below the elevation of the equilibrium line. We do not attempt to modify the model for the known differences that exist in ablation (for the same elevation and latitude) between East and West Greenland (e.g. Reeh, 1985; Weidick, 1995). The ablation model represents the net annual mass loss, which implicitly includes the melting of all the snow accumulated during winter as well as a net melting of surface ice during summer. The location of the equilibrium line on any part of the grid is determined from summaries available in the literature, which indicate close to a linear

Table 1. Surface-balance dataset (50 km grid)

\begin{tabular}{|c|c|c|c|c|c|c|c|c|}
\hline \multirow[t]{3}{*}{ Physiographic entity } & \multirow[t]{2}{*}{ Gridpoint } & \multicolumn{2}{|c|}{ Area } & \multicolumn{5}{|c|}{$\begin{array}{l}\text { Surface balance } \\
\text { Sominal }\end{array}$} \\
\hline & & Nominal & Adjusted & Mean & $S D$ & Min. & Max. & Mean \\
\hline & $\mathcal{N}$ & $10^{6} \mathrm{~km}^{2}$ & $10^{6} \mathrm{~km}^{2}$ & $\mathrm{~kg} \mathrm{~m}^{-2} \mathrm{a}^{-1}$ & $\mathrm{~kg} \mathrm{~m}^{-2} \mathrm{a}^{-1}$ & $\mathrm{~kg} \mathrm{~m}^{-2} \mathrm{a}^{-1}$ & $\mathrm{~kg} \mathrm{~m}^{-2} \mathrm{a}^{-1}$ & $\mathrm{~kg} \mathrm{~m}^{-2} \mathrm{a}^{-1}$ \\
\hline Dry snow and upper perc. fac. & 443 & 1.1075 & 1.1099 & 242 & 114 & 92 & 845 & 241 \\
\hline Lower percolation facies ${ }^{*}$ & 177 & 0.4425 & 0.4316 & 325 & 222 & 21 & 1500 & 321 \\
\hline Zone of net accumulation & 620 & 1.5500 & 1.5415 & 266 & 158 & 21 & 1500 & 263 \\
\hline Zone of net ablation & 62 & 0.1550 & 0.1497 & -1267 & 986 & -5000 & 0 & -1259 \\
\hline Conterminous ice sheet & 682 & 1.7050 & 1.6913 & 127 & 552 & -5000 & 1500 & 128 \\
\hline
\end{tabular}

\footnotetext{
* Includes zones of wetted facies and superimposed ice. A new drawing of the equilibrium line indicates a smaller area $(N=161$, reducing the overall area of net accumulation $(N=603)$ and increasing the area of net ablation $(N=79)$, with adjusted mean surface values of $267 \mathrm{and}^{(-)} 1015 \mathrm{~kg} \mathrm{~m}^{2} \mathrm{a}^{-1}$, respectively.
} 

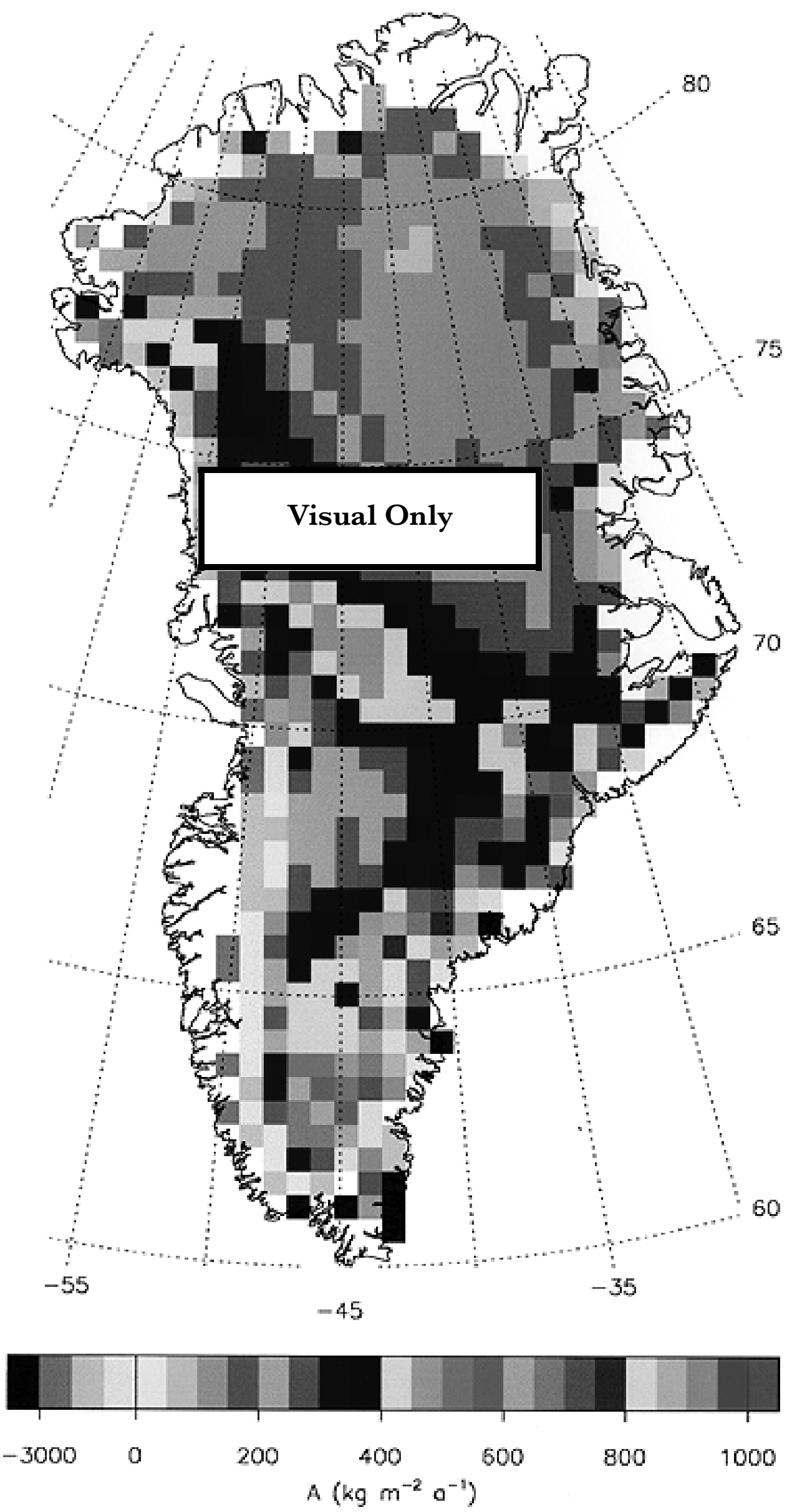

Fig. 2. Distribution of surface mass balance on the $50 \mathrm{~km}$ gridpoints $(N=682)$ of the conterminous Greenland ice sheet. 


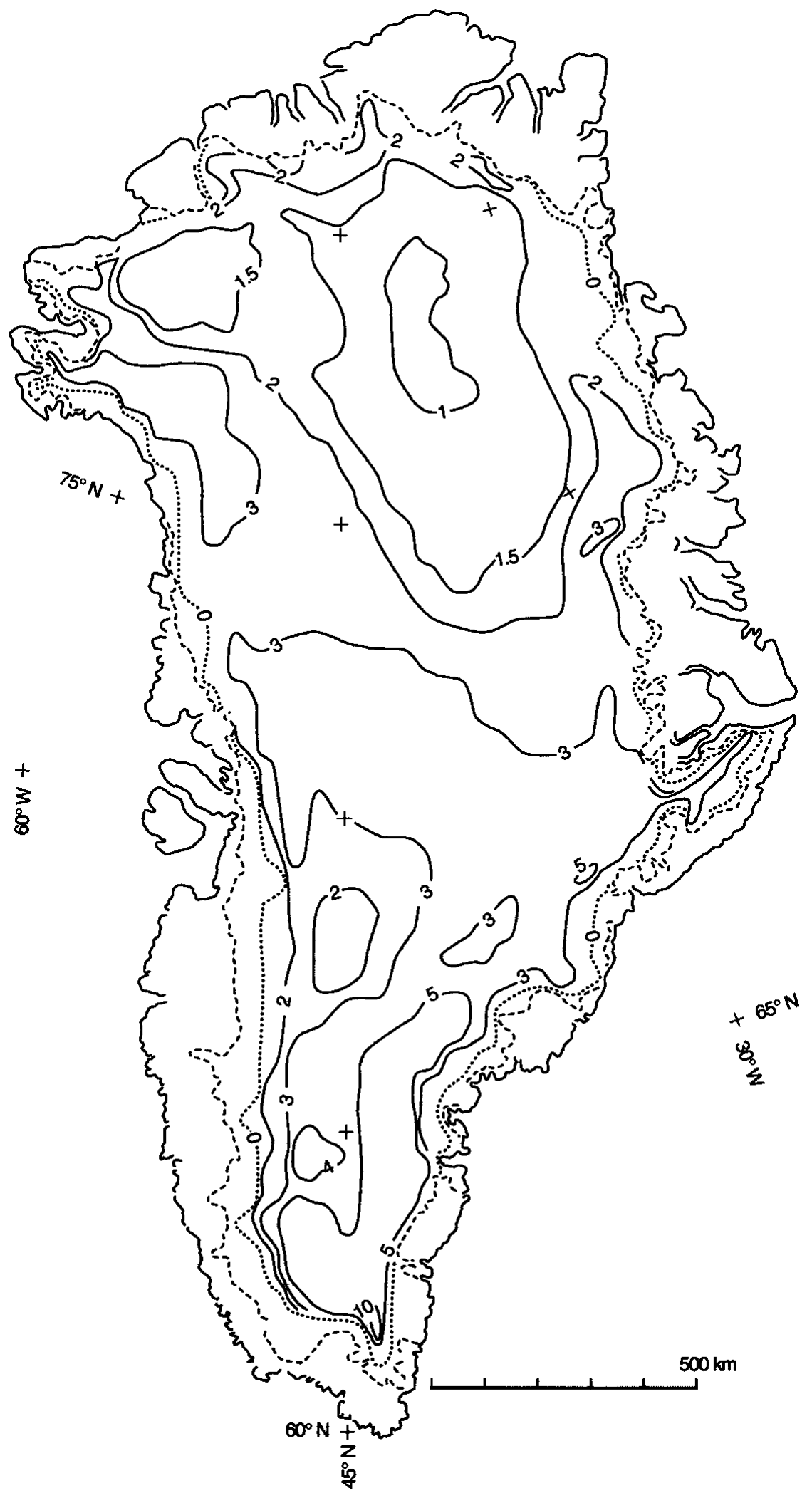

Fig. 3. Contoured distribution of surface mass balance on the Greenland ice sheet, showing the outer coastline, the ice-sheet terminus (dashed line) and the balance isopleths labeled in $100 \mathrm{~kg} \mathrm{~m}^{-2} a^{-1}$. The location of the equilibrium line (dotted line) is drawn to indicate relative difference in the width of the zone of net ablation rather than exact location of the line.

change from $300 \mathrm{~m}$ a.s.l. at $82^{\circ} \mathrm{N}$ to $1800 \mathrm{~m}$ a.s.l. at $61^{\circ} \mathrm{N}$ (Giovinetto and Zwally, 1996).

The remaining gridpoint locations $(N=177)$ lie on the area between the equilibrium line and the intra-percolation line. This area, which includes the zones of upper percolation and wetted facies as well as of superimposed ice, is referred to herein as the zone of intra-percolation facies. For the lower percolation zone, we obtain surface-balance values by visual interpolation from the isopleth pattern drawn on the basis of field data (Ohmura and Reeh, 1991; $N=177$ ). The values for approximately one-third of the locations were modified by linear interpolation that is forced to a balance of $0 \mathrm{~kg} \mathrm{~m}^{-2} \mathrm{a}^{-1}$ at the equilibrium line. However, this is an approximation, because spatial changes of the rate are not necessarily linear (e.g. Mock, 1967; Braithwaite, 1980), particularly on either side of the equilibrium line. 


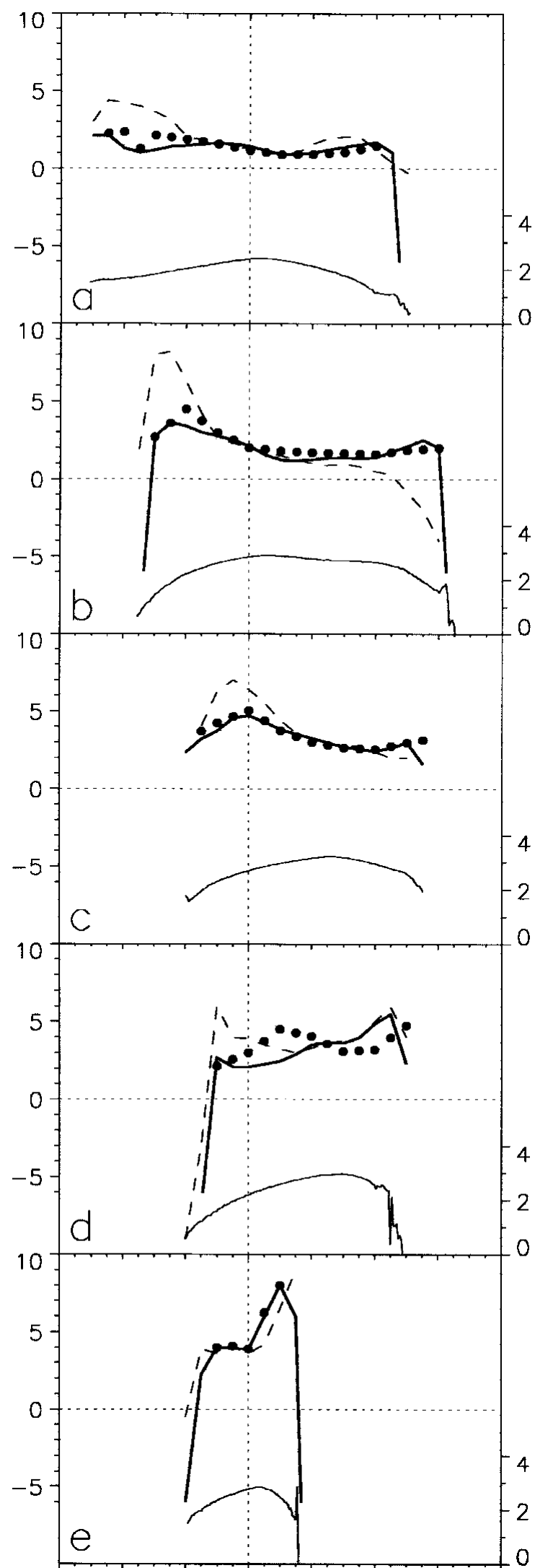

Fig. 4. Surface mass-balance profiles across the Greenland ice sheet based on $50 \mathrm{~km}$ gridlines perpendicular to the $45^{\circ} \mathrm{W}$ meridian (abscissa, $0 \mathrm{~km}$; distances in $100 \mathrm{~km}$ West (signed negative) and East) at latitudes of (a) $78.94^{\circ} \mathcal{N}$, (b) $75.75^{\circ} \mathcal{N}$, (c) $71.67^{\circ} \mathcal{N}$, (d) $68.98^{\circ} \mathcal{N}$ and (e) $64.10^{\circ} \mathcal{N}$. Balance profiles (left ordinate in $100 \mathrm{~kg} \mathrm{~m}^{-2} a^{-1}$ ) from this study (thick solid line), Radok and others (1982) (dashed line) and Ohmura and Reeh (1991) (dotted line). Surface elevation profiles (right ordinate in $\mathrm{km}$ ) (thin solid line) are from elevation maps from ERS-1 radar altimetry.
The descriptive statistics for the new balance dataset are listed in Table 1, as well as a summary of the derived mean balance estimates, principally a mean balance of $263 \mathrm{~kg} \mathrm{~m}^{-2}$ $\mathrm{a}^{-1}$ for the accumulation zone (area above the equilibrium line) and a mean balance of $(-) 1259 \mathrm{~kg} \mathrm{~m}^{-2} \mathrm{a}^{-1}$ for the ablation zone (area between the equilibrium line and the ice terminus). The mean balance for the conterminous ice sheet is $128 \mathrm{~kg} \mathrm{~m}^{-2} \mathrm{a}^{-1}$. The implications of the new balance estimates are discussed in the following section.

The new balance values supersede previous values obtained with a similar approach (Giovinetto and Zwally, 1996), but with the following changes in procedure:

use of a $50 \mathrm{~km}$ grid database (vs a $100 \mathrm{~km}$ grid database) use of the area scale factor to adjust for deformation in the map projection (vs use of the nominal grid square area)

use of the emissivity model (Zwally and Giovinetto, 1995) for the area bound by the intra-percolation line (vs the dry-snow line)

use of the ablation model (Braithwaite, 1980) for the area seaward of the equilibrium line (vs no estimate for that area)

use of interpolated values from the compilation of Ohmura and Reeh (1991) for the zone of lower percolation facies (vs the zones of upper percolation as well as lower percolation facies)

adjustment of values interpolated from Ohmura and Reeh (1991) for locations close to the equilibrium line to fit a linear change of the rate and a value of $0 \mathrm{~kg} \mathrm{~m}^{-2} \mathrm{a}^{-1}$ at the equilibrium line (vs a cross-board reduction of one-eighth of the balance rate applied to all locations close to the equilibrium line).

These changes introduce differences in balance values for particular locations on the order of $100 \mathrm{~kg} \mathrm{~m}^{-2} \mathrm{a}^{-1}$, but only a small reduction $\left(-10 \mathrm{~kg} \mathrm{~m}^{-2} \mathrm{a}^{-1}\right)$ in the mean balance over the accumulation zone. The previous value was at $273 \mathrm{~kg} \mathrm{~m}^{-2} \mathrm{a}^{-1}$ for a nominal area of $1.58 \times 10^{6} \mathrm{~km}^{2}$ or $431 \mathrm{Gt} \mathrm{a}^{-1}$ total.

Visually interpolated isopleths were drawn on the basis of grid balance values to show the distribution as a continuous surface, particularly along the coastal zone, on either side of the equilibrium line (Fig. 3).Visual interpolation and manual drawing are required because contouring algorithms are not sufficiently sensitive to the combination of a coarse-grid dataset and the steep gradient of the balance rate in the coastal zone.

\section{COMPARISON OF RESULTS}

We compare the surface balance distribution with two preceding distributions. One previous distribution, by Radok and others (1982), used models in a manner analogous to our approach. The other distribution, by Ohmura and Reeh (1991), was based on visual interpolation of field data. Profiles of the surface balances from these three balance distributions along five east-west profiles are shown in Figure 4.

Our isopleth pattern, as well as the magnitude of the balance values, agrees in general with the pattern produced by Ohmura and Reeh (1991) over most of the interior of the ice sheet. However, the isopleth values along the peripheral area, extending approximately $200 \mathrm{~km}$ inland from the ice terminus, show a large disparity, mainly because we show 


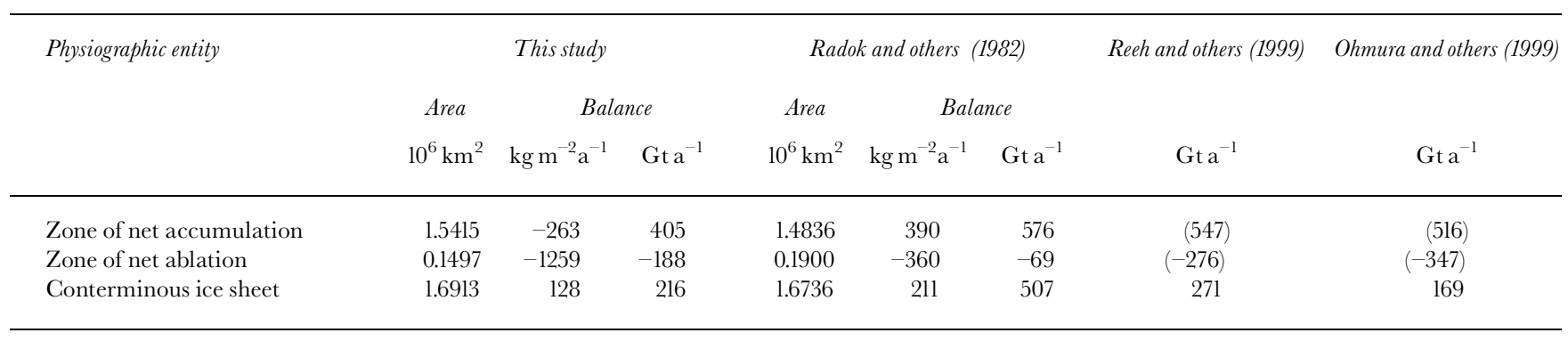

surface balance, whereas Ohmura and Reeh (1991) show gross accumulation (cf. Fig. 1). Because balance and gross accumulation are two distinct variables, our comparison with the isopleth pattern of Ohmura and Reeh (1991) (full circles in Fig. 4) is limited to a distance of approximately $50-100 \mathrm{~km}$ inland from the equilibrium line. The eastern and western ends of each balance profile for Ohmura and Reeh correspond mostly to locations on the lower percolation. The relatively large disparity between balance values for the cross-section at $68.98^{\circ} \mathrm{N}$ (Fig. 4d) may have a number of causes, including errors inherent in the field and remotely sensed datasets and their interpretations. Moreover, natural temporal variations cannot be discounted. For the remotely sensed data, variations in the temperature field for 1979 or in melting-freezing phenomena at or near the surface in the few years prior to or during collection of the ESMR data (1973-76) could be factors. For interpolations of field data, the use of data representing various short periods of time could be a factor in the differences.

Our isopleth pattern is also in general agreement with the pattern produced by Radok and others (1982). However, their values in the interior are approximately $50 \%$ larger than ours. This difference is not readily evident on the profiles in Figure 4, except along the western coastal region, but it is evident in a comparison of estimates of surface balance obtained from the distributions (Table 2). Radok and others (1982) used the field data available at the time, but relied on models to derive the grid values for the areas of net accumulation and net ablation (respectively, the models developed by Mock (1967) and by Budd and Smith (1981)).

For comparison, we selected the estimates made by Radok and others (1982) that separated the areas of net accumulation and net ablation at the equilibrium line, as we have. Their separation gave $89 \%$ accumulation area and $11 \%$ ablation area (ratio of $8: 1$ ). Although similar to our values of $91 \%$ and $9 \%$ (ratio of 10:1), the respective ablation areas differ by $20 \%$. Their other estimate that separated the areas at the saturation line gave $75 \%$ accumulation and $25 \%$ ablation. The difference in the total area of the conterminous ice sheet used in the balance estimates contributes little to the overall difference. The main factors are the difference between the accumulation/ablation-area ratio $(8: 1 \mathrm{vs} 10: 1)$ and the disparity in the mean rates of ablation. Our ablation estimate of $-188 \mathrm{Gt} \mathrm{a}^{-1}$ is $172 \%$ larger than their $-69 \mathrm{Gta}^{-1}$, whereas our accumulation estimate of $405 \mathrm{Gt} \mathrm{a}^{-1}$ is only $30 \%$ smaller than their $576 \mathrm{Gt} \mathrm{a}^{-1}$.

Since this study and Radok and others (1982) split the accumulation and ablation zones at the equilibrium line, columns 2-6 in Table 2 can be compared for all terms. However, the balance terms listed for Ohmura and others (1999) and Reeh and others (1999) are not defined by a split at the equilibrium line. Thus, the balance estimates for the conterminous ice sheet are directly comparable across the table, but the separate estimates of accumulation and ablation are not. Therefore, the accumulation and ablation terms listed in the last two columns are shown in parentheses.

Our estimate of surface balance for the whole area of the conterminous ice sheet $\left(216 \mathrm{Gt} \mathrm{a}^{-1}\right)$ is $57 \%$ smaller than an estimate of Radok and others (1982) (507 Gt a ${ }^{-1}$ ), and 20\% smaller than the estimate of Reeh and others (1999) $\left(271 \mathrm{Gt} \mathrm{a}^{-1}\right)$. In contrast, it is $28 \%$ larger than the $169 \mathrm{Gt} \mathrm{a}^{-1}$ estimate of Ohmura and others (1999). The difference between our overall estimate and Reeh and others' (1999) is $-55 \mathrm{Gta}^{-1}$, and between ours and Ohmura and others' (1999) $+47 \mathrm{Gta}^{-1}$. Both of these differences are approximately within the composite variation of previous estimates of $\pm 50 \mathrm{Gta}^{-1}$, which is appropriate for comparing two balance estimates. This composite variation of estimates is calculated from the variation of estimates of accumulation $\left( \pm 20 \mathrm{Gt} \mathrm{a}^{-1}\right)$ and of ablation $\left( \pm 30 \mathrm{Gt} \mathrm{a}^{-1}\right)$ reported during the last two decades (referenced in this and the following section), but excluding the findings of this study and of the study by Radok and others (1982)). Including the accumulation and ablation terms from our study and from Radok and others (1982) would artificially increase the calculated variations, because of the aforementioned differences in defining the accumulation and ablation terms. In the other studies, the accumulation estimates are for the whole area of the ice sheet, combining estimates of net accumulation for the interior and of gross accumulation for the area coastal zone. The other estimates of ablation are the gross ablation for the coastal zone. The resulting composite variation is approximately $\pm 35 \mathrm{Gta}^{-1}$ for any one particular balance estimate, and approximately $\pm 50 \mathrm{Gta}^{-1}$ for the difference between any two surface balance estimates.

\section{GONGLUDING REMARKS}

Substantial differences in the various estimates of surface balance for Greenland are introduced, primarily by differences in the delineation of the equilibrium line that determines the division of areas of net accumulation and net ablation, as well as in the models used to assess ablation. Secondary differences are introduced by differences in the models used to obtain accumulation, and in the criteria used for the interpolation of field data. Our microwave emissivity model for accumulation, which is calibrated to field data, has provided in effect an improved method of interpolating field data and for extrapolation into areas of sparse data. Whereas our balance estimate for the accumulation zone $\left(263 \mathrm{~kg} \mathrm{~m}^{-2} \mathrm{a}^{-1}\right)$ is within $33 \%$ of the estimate by Radok and others (1982) (390 $\mathrm{kg} \mathrm{m}^{-2} \mathrm{a}^{-1}$ ) obtained using the 
multivariate models described by Mock (1967), comparison suggests that the ablation model of Braithwaite (1980) produces larger ablation values than the model of Budd and Smith (1981) by a factor of approximately 3 .

The differences between our estimate of surface balance and two of the latest estimates (Ohmura and others, 1999; Reeh and others, 1999) are approximately within the calculated composite variation of other estimates. On a broader perspective, our surface balance estimate of $216 \mathrm{Gt} \mathrm{a}^{-1}$, compared with other estimates in which assessments of both accumulation and ablation were made by the same author $(\mathrm{s})$ (as opposed to estimates based on combinations of separate assessments of either accumulation or ablation by different authors), shows agreement with the estimates of Weidick (1985) (215 $\mathrm{Gt} \mathrm{a}^{-1}$ ) and Van de Wal (1996) (223 Gt a $\left.{ }^{-1}\right)$. Except for the estimate of Ohmura and others (1999) (169 Gt a ${ }^{-1}$ ), our estimate is smaller than the estimates of Radok and others (1982) (507 $\mathrm{Gt} \mathrm{a}^{-1}$ ), Huybrechts and others (1991) $\left(283 \mathrm{Gt} \mathrm{a}^{-1}\right)$, Reeh and others (1999) (271 Gt a $\left.{ }^{-1}\right)$ and Janssens and Huybrechts (2000) (261 Gta ${ }^{-1}$ ). Thus, its use in massbudget studies, which also require estimates of ice discharge into the ocean, would reduce the resulting mass-budget estimates. For example, substituting our accumulation estimate in the latest budget estimate of Reeh and others (1999) would change their findings from a mass balance near zero (i.e. equilibrium) to a negative balance of $55 \mathrm{Gt} \mathrm{a}^{-1}$, suggesting a positive contribution of the Greenland ice sheet to sealevel change of $0.15 \mathrm{~mm} \mathrm{a}^{-1}$.

\section{AGKNOWLEDGEMENTS}

The authors acknowledge the contributions of S. Bhardwaj, M. Beckley, M. Cheng, C. Conrad, J. DiMarzio, S. Fiegles and J. Saba.

\section{REFERENCES}

Benson, C. S. 1962. Stratigraphic studies in the snow and firn of the Greenland ice sheet. SIPRE Res. Rep. 70.

Braithwaite, R.J. 1980. Regional modelling of ablation in West Greenland. Gronlands Geol. Undersøgelse. Rapp. 98.

Budd, W. F. and I. N. Smith. 1981. The growth and retreat of ice sheets in response to orbital radiation changes. International Association of Hydrological Sciences Publication 131 (Symposium at Canberra 1979-Sea Level, Ice and Climatic Change), 369-409.

Comiso, J. C. 1994. Surface temperatures in the polar regions from Nimbus 7 temperature humidity infrared radiometer. 7. Geophys. Res., 99(C3), $5181-5200$.
Giovinetto, M. B. and H. J. Zwally. 1996. An assessment of the mass budgets of Antarctica and Greenland using accumulation derived from remotely sensed data in areas of dry snow. Z. Gletscherkd. Glazialgeol., 31, Part 1, 1995, 25-37.

Huybrechts, P., A. Letréguilly and N. Reeh. 1991. The Greenland ice sheet and greenhouse warming. Global and Planetary Change, 3(4), 399-412.

Janssens, I. and P. Huybrechts. 2000. The treatment of meltwater retardation in mass-balance parameterizations of the Greenland ice sheet. Ann. Glaciol., 31 (see paper in this volume).

Mock, S. J. 1967. Calculated patterns of accumulation on the Greenland ice sheet. F. Glaciol., 6(48), 795-803.

Oeschger, H. and C. C. Langway, Jr, eds. 1989. The environmental record in glaciers and ice sheets. Chichester, etc., John Wiley and Sons. (Wiley-Interscience Publication, Physical, Chemical, and Earth Sciences Research Report 8.)

Ohmura, A. 1987. New temperature distribution maps for Greenland. Z Gletscherkd. Glazialgeol., 23(1), 1-45.

Ohmura, A. and N. Reeh. 1991. New precipitation and accumulation maps for Greenland. 7. Glaciol., 37(125), 140-148.

Ohmura, A., M. Wild and L. Bengtsson. 1996. A possible change in mass balance of Greenland and Antarctic ice sheets in the coming century. f. Climate, 9(9), 2124-2135.

Ohmura, A., P. Calanca, M. Wild and M. Anklin. 1999. Precipitation, accumulation and mass balance of Greenland ice sheet. Z. Gletscherkd. Glazialgeol., 35(1), 1-20.

Parkinson, C. L., J. C. Comiso, H. J. Zwally, D. J. Cavalieri, P. Gloersen and W. J. Campbell. 1987. Arctic sea ice, 1973-1976: satellite passive-microwave observations. Washington, DC, National Aeronautics and Space Administration. Scientific and Technical Information Branch. (NASA SP-489.)

Pinther, M., ed. 1975. Map of the Arctic region. (Scale 1:5M.) New York, American Geographical Society. (The World Sheet 14.)

Radok, U., R. G. Barry, D. Jenssen, R. A. Keen, G. N. Kiladis and B. McInnes. 1982. Climatic and physical characteristics of the Greenland ice sheet. Part I and II. Boulder, CO, University of Colorado. Cooperative Institute for Research in Environmental Sciences.

Reeh, N. 1985. Greenland ice-sheet mass balance and sea-level change. In Glaciers, ice sheets, and sea level: effect of a $\mathrm{CO}_{2}$-induced climatic change. Report of a Workshop held in Seattle, Washington, September 13-15, 1984. Washington, DC, U.S. Department of Energy. Office of Energy Research, 155-171. (Report DOE/ER/60235-1.)

Reeh, N., C. Mayer, H. Miller, H. H. Thomsen and A. Weidick. 1999. Present and past climate control on fjord glaciations in Greenland: implications for IRD-deposition in the sea. Geophys. Res. Lett., 26(8), 10391042.

Van de Wal, R. S.W. 1996. Mass-balance modelling of the Greenland ice sheet: a comparison of an energy-balance model and a degree-day model. Ann. Glaciol., 23, 36-45.

Weidick, A. 1985. Review of glacier changes in West Greenland. Z Gletscherkd. Glazialgeol., 21, 301-309.

Weidick, A. 1995. Greenland. U.S. Geol. Surv. Prof. Pap. 1386-C, C1-C93.

Zwally, H.J. 1977. Microwave emissivity and accumulation rate of polar firn. F. Glaciol., 18(79), 195-215.

Zwally, H. J. and A. C. Brenner. 1999. The role of satellite radar altimetry in the study of ice sheet dynamics and mass balance. In Fu, L.-L., ed. Satellite altimetry and earth sciences. New York, Academic Press Inc., 351-369.

Zwally, H.J. and M. B. Giovinetto. 1995. Accumulation in Antarctica and Greenland derived from passive-microwave data: a comparison with contoured compilations. Ann. Glaciol., 21, 123-130. 